\title{
IRF6 mutations may not be a major cause of Van der Woude syndrome in India
}

\author{
Gayatri A. Moghe $\cdot$ Simratvir Mauli
}

Received: 19 August 2010 / Accepted: 25 August 2010/Published online: 16 September 2010

(C) Springer-Verlag 2010

We read with interest the article by GB Ferrero et al. on Van der Woude syndrome (VWS) reporting a novel mutation [2] in the IRF6 gene coding region. Nearly 100 mutations in the coding region of the gene have been reported from several populations in different geographical regions of the globe. So far, $I R F 6$ is the only gene shown to be associated with VWS as a dominant trait with variable penetrance and expressivity. However, direct sequencing of all coding regions and exon-intron boundaries of the IRF6 gene have not shown any mutation in an Indian cohort $(n=13)$ [1]. Another Indian study of a VWS pedigree conducted by the authors also corroborates the findings that critical region of the 1q32-q41 may not be causal for VWS in multi-ethnic and diverse Indian populations [3]. As VWS is the most common form of syndromic clefting, the possibility of stochastic factors modifying the expression of the syndrome cannot be denied. However, the tendency towards a publication bias and the "file drawer effect" may sometimes result in inadequate outcome reporting. Published studies may not be truly representative of all valid studies undertaken, and this bias may distort meta-analyses and systematic reviews of large numbers of studies - on which evidence-based medicine increasingly relies. This further compounds the genetic complexity of the one of the most common orofacial clefting syndromes, which needs to be studied in greater depth before any conclusion can be drawn. Therefore the authors are of the opinion that it is too premature to use only IRF6 mutations as diagnostic/ predictive tests which are being offered by some companies with vested interests.

Conflict of interest The authors have no financial interest with any organization which has sponsored the research.

\section{References}

1. Ali A, Singh SK, Raman R (2009) Coding region of IRF6 gene may not be causal for Van der Woude syndrome in cases from India. Cleft Palate-Craniofac J 46(5):541-544. doi:10.1597/08-202.1

2. Ferrero GB, Baldassarre G, Panza E, Valenzise M, Pippucci T, Mussa A, Pepe E, Seri M, Silengo MC (2010) A heritable cause of cleft lip and palate-Van der Woude syndrome caused by a novel IRF6 mutation. Review of the literature and of the differential diagnosis. Eur J Pediatr 169:223-228. doi:10.1007/s00431-0091011-3

3. Moghe GA, Kaur MS, Thomas AM, Raseswari T, Swapna M, Rao L (2010) The role of $9 \mathrm{qh}+$ in phenotypic and genotypic heterogeneity in a Van der Woude syndrome pedigree. J Indian Soc Pedod Prev Dent 28(2):104-109. doi:10.4103/09704388.66749

\footnotetext{
G. A. Moghe $(\bowtie)$

Department of Pediatric Dentistry, Panineeya Institue of Dental

Sciences and Research Centre, Senior Lecturer,

Street No: 5, Kamalanagar, Dilsukhnagar,

Hyderabad 500060, Andhra Pradesh, India

e-mail: drgayatrimoghe@gmail.com

S. Mauli

Department of Pediatric Dentistry,

BRS Dental College and Hospital,

Panchkula, Haryana, India
} 